\title{
Dominantly inherited cerebral dysplasia: arachnoid cyst associated with mild mental handicap in a mother and her son
}

\author{
J L Tolmie, Ruth Day, Briony Fredericks, P Galea, A W G Moffett
}

\begin{abstract}
We report a mother and son who each presented in infancy with hypotonia and global developmental delay. Subsequently, in both subjects, mild mental handicap was diagnosed in association with temporal lobe arachnoid cysts. Mendelian inheritance of this phenotype seems likely and macroscopic cerebral dysplasia in general may be underdiagnosed in people with familial, mild mental handicap.

$(F$ Med Genet 1997;34:1018-1020)
\end{abstract}

Keywords: cerebral dysplasia; dominant inheritance; arachnoid cyst; mental handicap

Mild mental handicap is frequently familial, ${ }^{12}$ but clear evidence of underlying monogenic inheritance is rarely present. ${ }^{3}$ In affected families, the effects of assortive mating, poor socioeconomic status, and possible polygenic influences usually combine to obscure evidence of Mendelian inheritance. Arachnoid cysts, although rarely familial, ${ }^{4-6}$ are not uncommon, occurring in up to $0.5 \%$ of cranial apparent and EEG examination was undertaken when the diagnosis of Angelman syndrome was being considered. This latter investigation showed asymmetrical electrical activity, so brain CT scan was performed when the proband was 10 months old (fig 1). Initially, the films were reported as showing mainly focal bitemporal lobe porencephaly with more marked changes on the left side; these changes were thought to be the consequence of an unidentified prenatal destructive process. However, the mother also had radiological examinations performed after specific questioning indicated that she did not walk until 2 years of age and had had mild learning difficulties which necessitated special schooling. By 12 years of age she could tell the time. The mother's CT scan showed similar temporal lobe abnormality giving the appearance of a left temporal lobe arachnoid cyst (fig 2). Examination of the mother's old medical records confirmed that in her first year she was thought to have "hypotonic cerebral palsy" and her developmental milestones were globally delayed. The old hospital records further indicated that the mother had been placed in a foster home at the age of 3 months but nothing was known of her birth or family history. Her son, when last examined at 3 years, had improved tone and gross motor skills, he could walk, but said only a few single words.

This case report illustrates how the result of one investigation (EEG examination), ordered when investigating the possibility of an alternative diagnosis (Angelman syndrome), led to a second test (brain CT imaging) which showed unsuspected, inherited cerebral dysplasia. Does this experience have general relevance for the intensity of medical investigations carried out on people with mild mental handicap? Typically, mildly intellectually disabled people are physically well and present to community based learning disability services or the educational psychology service, rather than a hospital based clinic. If one or both parents also have intellectual impairments, a family may be less likely to request genetic advice and referral to the genetic clinic is seldom offered. Consequently, few or no medical investigations might be arranged in cases of familial mild mental handicap and issues which should arise, such as the question of a syndrome diagnosis or a specific genetic counselling query, are easily overlooked. However, our experience underlines the primary importance of obtaining a detailed history for each relative and close scrutiny of \footnotetext{
computed tomography (CT) or magnetic resonance images (MRI).$^{78}$ Cysts are considered congenital, intra-arachnoid, leptomeningeal lesions that expand by CSF production. Small cysts are usually asymptomatic but larger cysts might present at any time from prenatal life through infancy and adulthood with head enlargement, symptoms of increased intracranial pressure, intracranial haemorrhage, or seizures. $^{7-10}$ In this case report, we present details of a mother and her son who each have mild learning disability in association with an unusual type of inherited brain dysplasia which has the appearance of temporal lobe arachnoid cyst.

The proband, a male child, was born at term by normal delivery and weighed $3620 \mathrm{~g}$. The mother was a healthy primiparous woman who had been adopted at birth and knew nothing of her family history. The pregnancy and puerperium were unremarkable and the infant presented at the age of 2 months with marked head lag. Examination showed a nondysmorphic, well grown infant with central hypotonia. Head circumference (OFC) was on the 75 th centile and the mother's OFC was on the 50 th centile. During the infant's first year, a battery of biochemical tests, blood chromosome analysis, and cranial ultrasound examination were performed and all gave normal results. Global delay in development was

Received 7 February 1997 Revised version accepted fo publication 7 May 1997

Andrew Street, East

A W G Moffett

Correspondence to

Correspon
} 


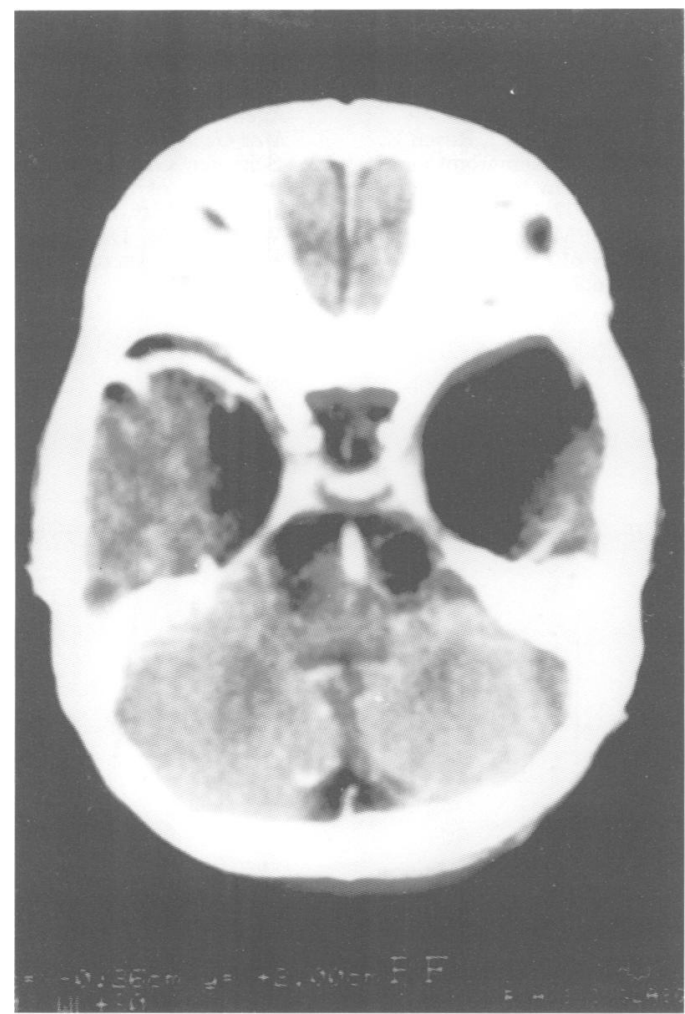

Figure 1 Axial CT with contrast showing bilateral temporal arachnoid cysts in the proband.

appropriate medical records, two time consuming tasks that are probably best accomplished at the genetic clinic.

In was notable that the initial battery of genetic and biochemical tests which were ordered gave normal results but the neuroimaging studies (originally not considered a front line investigation) showed the diagnosis and its inheritance. With hindsight, the important clinical clue to inherited brain dysplasia causing mild mental handicap was abnormal neurodevelopment in infancy, the "hypotonic cerebral palsy" which affected both mother and child. In fact, uncomplicated, mild mental handicap rarely presents in the first year of life,
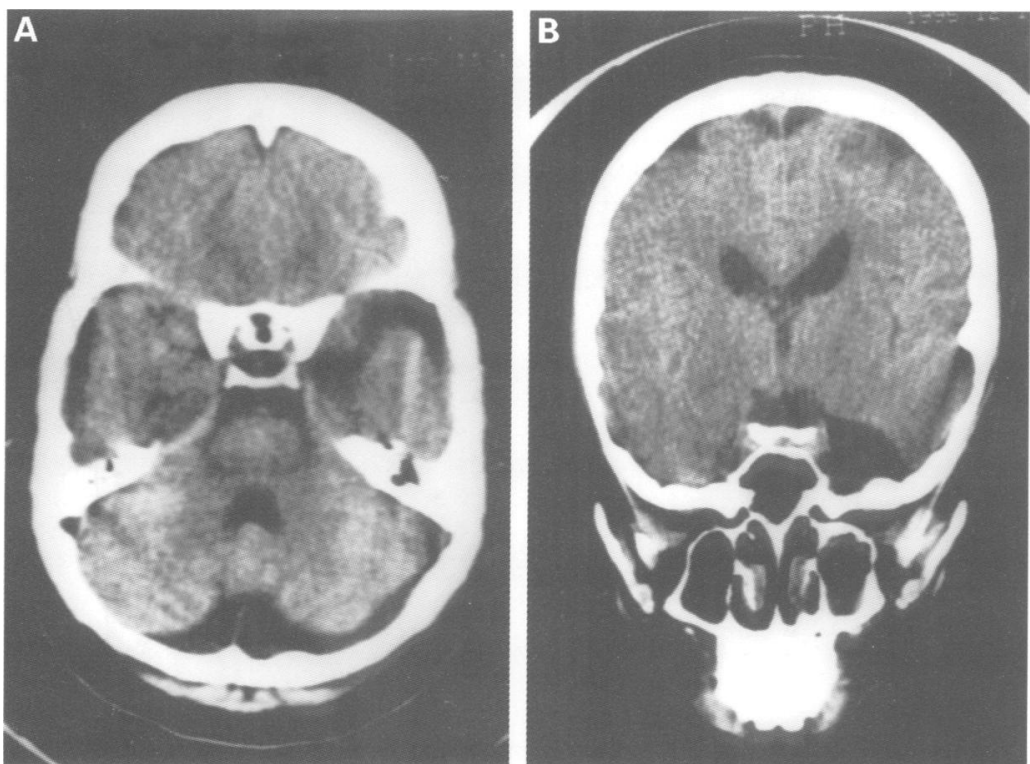

Figure 2 (A) Axial and (B) coronal CT showing left temporal arachnoid cyst in the proband's mother. so major diagnostic significance should be attached to delayed motor milestones or atypical neurological signs present in subjects with mild mental handicap; such observations constitute an indication for detailed neuroimaging studies in affected children and adults.

Since middle cerebral fossa arachnoid cyst usually occurs sporadically and causes no symptoms, ${ }^{8}$ in our family it seems most likely that the CT abnormality is a non-specific macroscopic marker (in the same way that agenesis of the corpus callosum ${ }^{11}$ or septum pellucidum abnormality ${ }^{12}$ might be in other instances) of subtle, inherited cerebral dysplasia affecting neurodevelopment and learning. There are few other reports of familial arachnoid cyst: Handa et $a l^{4}$ described two male sibs with bilateral cysts who presented in early childhood with head enlargement that was treated by surgical shunt operations. These brothers may have had normal development before their presentation, but one was mentally and physically retarded afterwards. Both parents were healthy and had normal sized heads. Pomeranz et at reported two male and one female sibs; both males presented in early childhood with rapidly increasing head size and underwent surgery. One had slow neurodevelopment subsequently, the other had "borderline normal" development. Their similarly affected sister was asymptomatic when she was diagnosed at the age of 5 years. Confusingly, in a diagram of the family tree, the authors indicated that the mother of these three sibs was also affected although no information was given in the text. There is one other published Japanese report of 5 year old and 3 year old brothers with arachnoid cyst. ${ }^{6}$ Finally, it seems most likely that an autosomal recessive condition affected two sibs who each had large, unilateral arachnoid cyst, mental handicap, and microcephaly. ${ }^{13}$ Although the parents of these sibs were not known to be consanguineous, their ancestors came from the same region and had surnames in common. These rare observations of familial arachnoid cyst do not permit firm conclusions about inheritance, but underlying clinical and genetic heterogeneity seems likely. We believe that the main message which emerges from our report of concurrence of arachnoid cyst and mild mental handicap in a mother and her son is that in some cases mild learning disability may have a discernible Mendelian basis that is easily overlooked.

We thank Dr Michael Baraitser for reviewing the manuscript and making helpful suggestions.

1 Bundey S, Thake A, Todd J. The recurrence risks for mild idiopathic mental retardation. 7 Med Genet 1989;22:260-6.

2 Scott S. Mental retardation. In: Rutter M, Hersow L, Taylor E, eds. Child and adolescent psychiatry. 3rd ed. Oxford: Blackwell Scientific Publications, 1994:616-46.

3 Bundey S. Abnormal mental development. In: Rimoin DL, Connor JM, Pyeritz RE, eds. Emery and Rimoin's principles and practice of medical genetics. New York: Churchill Livingstone, 1996.

4 Handa J, Okamoto K, Sato M. Arachnoid cyst of the middle cranial fossa: report of bilateral cysts in siblings. Surg Neurol 1981;16:127-30.

5 Pomeranz S, Constantini S, Lubetzki-Korn IK, Amir N. Familial intracranial arachnoid cysts. Childs Nerv Syst 1991;7:100-2. 
6 Kuzuhara M, Shimura T, Yojima K, Nakazawa S, Honda K Two cases of arachnoid cyst in siblings. No To Hattatsu 1980;2:309.

7 Go KG. The diagnosis and treatment of intracranial arachnoid cysts. Neurosurg Quart 1995;5:187-204.

Parsch C, Krauss J, Hoffman E, Meixensberger J, Rosen K. Arachnoid cysts associated with subdural haematomas and hygromas: analysis of 16 cases, long-term follow-up and review of the literature. Neurosurgery 1997;40:483-90

9 Hassan J, Sepulveda W, Teixeira J, Cox PM. Glioependymal and arachnoid cysts - unusual causes of early ventriculomegaly in-utero. Prenat Diagn 1996;16:729-33.
10 Pascual-Castroviejo I, Pascual-Pascual SI. Bilateral arachnoid cysts, seizures and severe encephalopathy: case report. Neuropediatrics 1994;25:42-3.

11 Inbar D, Halpern G, Wietz $R$, Sadeh $M$, Shohat $M$. Agenesis of the corpus callosum in a mother and son. $A m \mathcal{F}$ Med Genet 1997;69:152-4.

12 Schaefer GB, Bodensteiner JB, Thompson JB. Subtle anomalies of the septum pellucidum and neurodevelopmental deficits. Dev Med Child Neurol 1994;36:554-9.

13 Wilson WG, Deponte KA, McIlhenny J, Dreifuss FE Arachnoid cysts in a brother and sister. $\mathcal{F}$ Med Genet 1988; 25:714-15. 